\title{
Utility of nutritional evaluation for the clinical risk assessment of postoperative complications. Does oncology need the NRS 2002 scale?
}

\author{
Patrycja Potyrała ${ }^{1}$, Zuzanna Ogonowska ${ }^{1}$, Agata Toboła ${ }^{1}$, Bartosz Cyman ${ }^{1}$, Marta Kiziak , \\ Nastazja Pilonis ${ }^{1}$, Aleksandra Szmajdzińska ${ }^{1}$, Andrzej Rutkowski ${ }^{2}$, Tomasz Olesiński ${ }^{2}$
}

Introduction. Malnutrition accompanies many cancers, especially those of the gastrointestinal tract, and significantly raises the risk of postoperative complications in cancer surgery. In Poland, hospitals are legally obliged to evaluate the nutritional status of their patients; one of the assessment tools used for this purpose is the NRS 2002 scale.

Aim. The primary objective of the study is to analyze the utility of the NRS 2002 scale in the risk assessment of postoperative complications in gastrointestinal cancers. In addition, the authors propose to determine whether the legal requirement to conduct nutritional assessments among hospitalized patients is complied with in clinical practice and to evaluate the risk of malnutrition in the study group.

Materials and methods. A detailed assessment was conducted on 226 patients who underwent surgery for upper (95 patients) and lower (131 patients) Gl tract cancers in 2015. The risk of complications was analyzed based on the nutritional risk score (NRS 2002) and the levels of albumin and total proteins in the serum before surgery. Compliance with the obligation to carry out nutritional assessments was evaluated on breast and GI cancer patients treated with surgery at the Institute of Oncology in Warsaw in two successive years.

Results. An NRS 2002 score of $\geq 3$ was shown to predict postoperative complications for both upper $\mathrm{Gl} \operatorname{tract}(\mathrm{p}<0.001)$ and colorectal cancers $(p<0.001)$. In upper GI cancers, complications were also more frequently observed at lower albumin $(p=0.018)$ and total protein $(p=0.025)$ levels in the serum.

Conclusion. The analysis shows that the NRS 2002 scale is useful in predicting the risk of postoperative complications in the treatment of upper and lower GI tract cancers.

NOWOTWORY J Oncol 2017; 67, 3: 174-179

Key words: malnutrition, postoperative complications, gastrointestinal cancers, NRS 2002

\section{Introduction}

Malnutrition accompanies many cancers, especially those of the gastrointestinal tract, and is not only one of the early symptoms of disease, but also the direct consequence of the condition and its treatment. Its causes include the loss of appetite, reduced food intake, metabolic changes due to the tumor and cancer-related chronic inflammation, as well as the side effects of cancer treatment, including surgery and chemo- and radiotherapy. In operated patients with $\mathrm{Gl}$ cancers, malnutrition is an independent risk factor for an increased incidence of complications, nosocomial infections, and perioperative mortality [1-6].

As of 1 January 2012, in accordance with the Ordinance of the Minister of Health of 15 September 2011, amended on 22 November 2013, Polish hospitals are obliged to carry out an assessment of the nutritional status of patients admitted to all their wards, including emergency rooms. For this purpose, they can use either of the following tools: the

\footnotetext{
1"Onkoma" Oncology Students' Club at the Clinic of Oncological Gastroenterology Maria Skłodowska-Curie Memorial Cancer Centre and Institute of Oncology, Warsaw, Poland ${ }^{2}$ Clinic of Oncological Gastroenterology, Maria Skłodowska-Curie Memorial Cancer Centre and Institute of Oncology Warsaw, Poland
} 
Subjective Global Assessment scale (SGA) or the Nutritional Risk Screening scale (NRS 2002). The simpler of the two, NRS 2002 (Annex 1), evaluates the degree to which the patient's nutritional status has deteriorated, including indicators such as the loss of body mass over three months, the BMI, food intake as a proportion of the daily requirement over the previous week, as well as the severity of the disease, which tends to be accompanied by an increased demand for nutrients. An additional risk factor for malnutrition is age above 70 years. On a scale from 0 to 7 , a score of $\geq 3$ indicates that nutritional therapy should be introduced [7].

\section{Purpose}

The primary objective of the study was to analyze the utility of the NRS 2002 scale in the risk assessment of postoperative complications in gastrointestinal cancers. In addition, the authors proposed to determine whether the legal requirement to conduct nutritional assessments among hospitalized patients is complied with in clinical practice and to evaluate the risk of malnutrition in the study group.

\section{Materials and methods}

In order to determine how often the NRS 2002 scale is completed and assess the risk of malnutrition among cancer patients, the study evaluated surgical units and clinical oncology wards in two different clinics of the Marie Skłodowska-Curie Cancer Centre and Institute of Oncology in Warsaw: the Clinic of Breast Cancer and Reconstructive Surgery (KNPi$\mathrm{ChR}$ ) and the Clinic of Oncological Gastroenterology (KGO). The assessment was conducted in 2014 and 2015. Over the studied period, the KNPiCHR performed surgery on 3,420 patients and administered conservative treatment to 16,744 , while the corresponding figures for the KGO were 1,888 and 4,054 , respectively. The exact distribution of admissions to specific wards is shown in Table I. The choice of clinics was dictated by the difference in nutritional risk in breast and gastrointestinal cancers.

A detailed assessment of the prognostic utility of the NRS 2002 scale was conducted on 226 patients with esophagus, stomach, colon, and rectum cancers who were operated on in 2015. The study group consisted of 76 women (34\%) and 150 men (66\%); the median age was 59 (29-85) years. The exact distribution of diagnosis, gender, and age is shown in Table II. Alongside the NRS 2002 scale, the risk of malnutrition was also assessed based on albumin (ALB)
Table I. Admissions to the Clinic of Breast Cancer and Reconstructive Surgery (KNPChR) and the Clinic of Oncological Gastroenterology (KGO)

\begin{tabular}{lcc}
\hline Clinic/Ward & Number of admissions per annum \\
& 2014 & 2015 \\
\hline KNPChR Surgical Ward & 1.733 & 1.687 \\
KNPChR Oncology Ward & 11.722 & 5.022 \\
KGO Surgical Ward & 864 & 1.024 \\
KGO Oncology Ward & 1.681 & 2.372 \\
\hline
\end{tabular}

and total protein (TP) levels in the serum, as measured a day before surgery. The threshold level for the NRS 2002 scale was defined as a score of 3 or more, and for ALB and TP — as $35 \mathrm{mg} \%$ and $66 \mathrm{mg} \%$, respectively.

All patients were prepared for surgery in the same manner, receiving special pre-operative nutritional treatment whenever their weight loss exceeded $10 \% / 3$ months, as well as undergoing anithrombotic prophylaxis and perioperative antibiotic therapy.

Data about surgical complications were gleaned from the prospective database of postoperative events kept at the Gastroenterology Clinic since 2010. These included the formation of abscesses at the surgical site, abdominal and scrotal wound infections, post-operative bleeding, anastomotic leaks, obstruction, UTIs, wound dehiscence, and other adverse symptoms, such as diarrhoea, rectovaginal fistulas, urinary retention, delayed peristalsis, urinary bladder dysfunctions, and sinus tachycardia.

The data were analyzed with the SPSS 15 statistical package; the Fisher's exact test was used whenever the number of cases was $\leq 10$, while the chi-square Pearson test was employed when the number greater.

\section{Results}

The utility of the NRS 2002 scale in nutritional assessment and the risk prognosis of postoperative complications was studied on patients with esophagus, stomach, and intestinal cancers who underwent surgery in 2015. Due to significant differences in the invasiveness of the procedure, perioperative risk, and the predicted number of malnourished patients, upper (esophagus and stomach) and lower (colon and rectum) tract cases were analyzed separately. The evaluation relied on the NRS 2002 scale, as well as the serum levels of albumin and total protein before surgery.

Table II. Characteristics of the study group: patient diagnosis (ICD 10), age, and sex

\begin{tabular}{lcccc}
\hline Diagnosis & $\begin{array}{c}\text { Number of patients } \\
(\mathbf{n})\end{array}$ & $\begin{array}{c}\text { Median age } \\
\text { (range) }\end{array}$ & Sex & \multicolumn{2}{c}{ Men n (\%) } \\
\hline C15-16 & 95 & $58(29-80)$ & $30(32 \%)$ & $65(68 \%)$ \\
C18-19 & 65 & $59(41-85)$ & $26(40 \%)$ & $39(60 \%)$ \\
C 20 & 66 & $56(39-79)$ & $20(30.3 \%)$ & $46(69.7 \%)$ \\
\hline
\end{tabular}


Table III. Surgery in stomach cancer patients

\begin{tabular}{lcccc}
\hline Parameter & $\begin{array}{c}\text { Postoperative } \\
\text { complications } \\
n(\%)\end{array}$ & $p$ & RR & $95 \% \mathrm{Cl}$ \\
& & & \\
\hline ALB & & & & \\
$<35(n=12)$ & $8(66.7)$ & 0.018 & 2.35 & $1.38-3.98$ \\
$\geq 35(n=81)$ & $23(28.4)$ & & & \\
TP & & & & \\
$<66(n=33)$ & $16(48.5)$ & 0.025 & 1.91 & $1.09-3.34$ \\
$\geq 66(n=59)$ & $15(25.4)$ & & & \\
NRS 2002 & & & & \\
$<3(n=64)$ & $7(10.9)$ & $<0.001$ & 7.57 & $3.69-15.52$ \\
$\geq 3(n=29)$ & $24(82.8)$ & & & \\
\hline
\end{tabular}

$\mathrm{n}$ - number of patients in the group; ALB - albumins in the serum; TP - total protein in the serum; NRS 2002 - nutritional risk score

In the upper tract group, both the NRS 2002 score $(p<0.001)$ and albumin level $(p=0.018)$ were identified as a risk factor for postoperative complications; the latter were observed in 31 patients (33\%), and mostly included septic symptoms $-10(10 \%)$ and respiratory failure - 9 (9\%). Detailed information can be found in Table III. In patients with lower tract cancers, only the NRS score $(p<0.001)$ was shown to have predictive utility. Postoperative complications, mostly septic (15 people, i.e. $11 \%$ ), were observed in 34 patients (18\%). Detailed data are shown in Table IV.

The analysis showed that head physicians largely failed to comply with the obligation of nutritional assessment. Compliance rates were higher in surgical departments: at the surgical ward of the KNPiChR, $63 \%(1,087 / 1,733)$ of admitted patients underwent assessment in 2014, as compared to $94 \%(1,583 / 1,687)$ a year later. In the analyzed period, the clinical oncology ward of the clinic used the NRS scale to evaluate as few as 5\% $(913 / 17,722)$ and $22 \%$ $(1,088 / 5,022)$ of patients, respectively (Fig. 1). The corresponding figures for the surgical ward of the KGO were $63 \%$
Table IV. Surgery in intestinal cancer patients (total)

\begin{tabular}{|c|c|c|c|c|}
\hline Parameter & $\begin{array}{c}\text { Postoperative } \\
\text { complications } \\
\text { n (\%) }\end{array}$ & $p$ & $\mathrm{RR}$ & $95 \% \mathrm{Cl}$ \\
\hline \multicolumn{5}{|l|}{ ALB } \\
\hline$<35(n=20)$ & $6(30.0)$ & 0.782 & 1.19 & $0.57-2.50$ \\
\hline$\geq 35(n=111)$ & $28(25.2)$ & & & \\
\hline \multicolumn{5}{|l|}{$\mathrm{TP}$} \\
\hline$<66(n=27)$ & $6(22.2)$ & 0.805 & 1.18 & $0.54-2.58$ \\
\hline$\geq 66(n=99)$ & $26(26.3)$ & & & \\
\hline \multicolumn{5}{|l|}{ NRS } \\
\hline$<3(n=111)$ & $18(16.2)$ & $<0.001$ & 4.93 & $3.06-7.94$ \\
\hline$\geq 3(n=20)$ & $16(80.0)$ & & & \\
\hline
\end{tabular}

$\mathrm{n}$ - number of patients in the group; ALB - albumins in the serum; TP - total protein in the serum; NRS 2002 - nutritional risk score

$(541 / 864)$ and $83 \%(845 / 1,024)$. Nutritional assessment was also rare at the clinical oncology ward of the KGO: as few as $8.5 \%$ of hospitalized patients $(144 / 1,681)$ were evaluated in 2014 and the figure further dropped to $8 \%(190 / 2,372)$ the following year (Fig. 2).

In order to evaluate the reliability of collected data, as compared to the proportion of malnourished patients predicted on the basis of available literature, the authors also performed an analysis of NRS scores obtained during the nutritional assessment conducted in the surgical wards of the two clinics in 2015. Due to the scarcity of data from clinical oncology units, a similar analysis could not be performed for patients undergoing conservative treatment. At the KNPiChR, 1,535 patients (94\%) obtained a score of less than 3; 92 (6\%) scored 3 or more. At the KGO, the corresponding values were 419 (49\%) and 426 (51\%), respectively (Fig. 3).

\section{Discussion}

With a significant impact on clinical outcome, malnutrition is now considered a major factor of poor prognosis

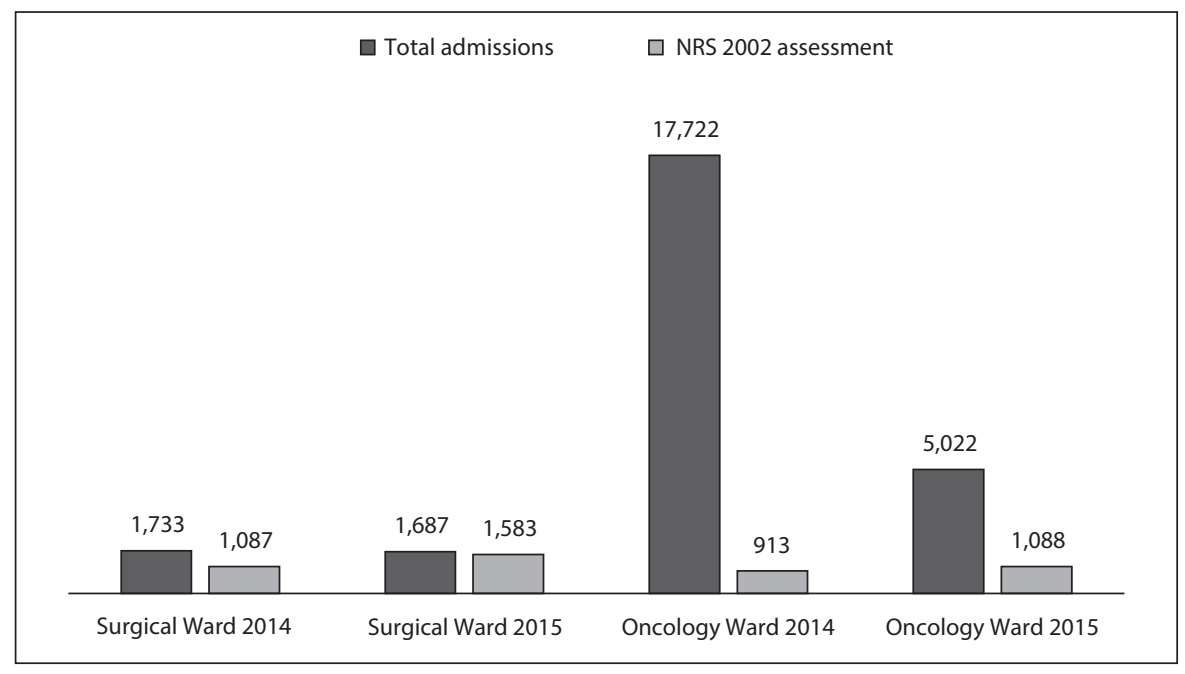

Figure 1. Nutritional assessment and the number of admissions to the Clinic of Breast Cancer and Reconstructive Surgery (KNPChR) 


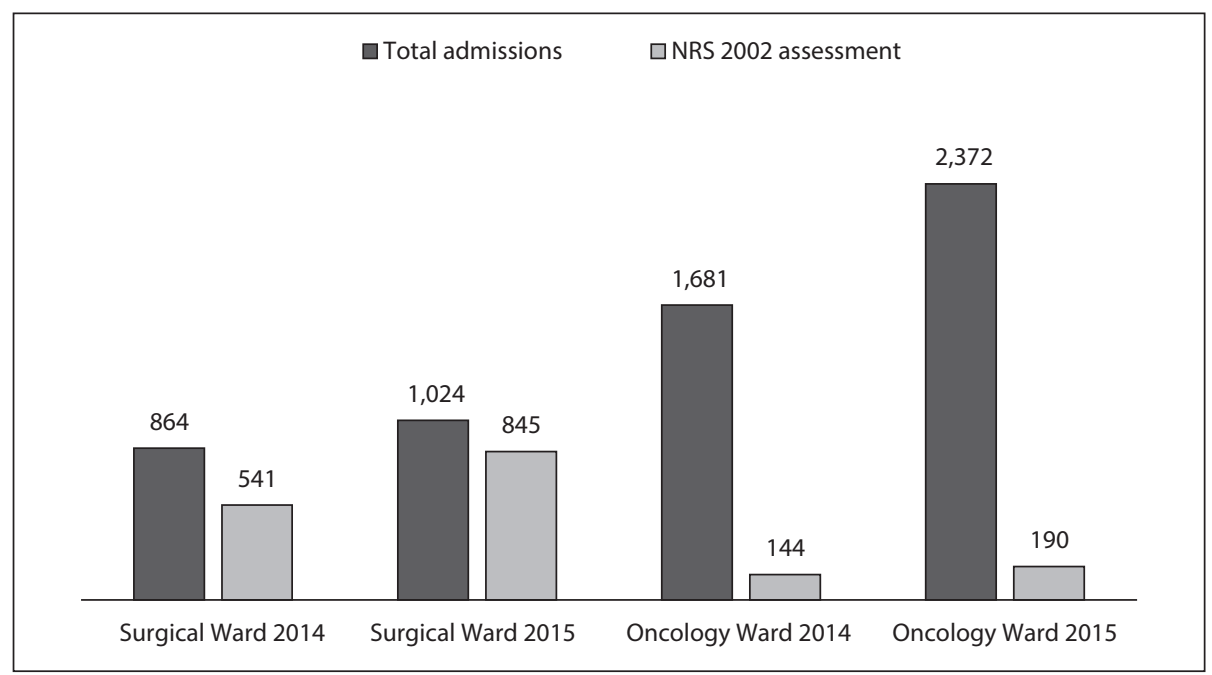

Figure 2. Nutritional assessment and the number of admissions to the Clinic of Oncological Gastroenterology (KGO)

in cancer therapy. Relatively frequent, the phenomenon occurs in $20-60 \%$ of cancer patients [1-3] and may considerably affect the quality of life and treatment results [8]; everyone, including those treated in highly developed countries of the European Union [9], is at risk. Importantly, malnutrition requires longer hospital stays, and, as a consequence, a more lengthy and expensive treatment process $[4,10-13]$, which may take up to twice as long as in properly nourished patients with the same diagnosis [2]. Its impact on postoperative events in digestive tract surgeries has been investigated by numerous clinical studies [3-6]. Associated complications may include slower, abnormal wound healing and often require the postponement of combined therapy, which negatively affects the final outcome of therapy [13]. The proper identification of high-risk patients and their nutritional treatment may improve clinical outcomes, shorten hospitalization time, reduce the frequency of complications, and lower perioperative mortality rates $[2,4,8,10,11,14]$.

The choice of an appropriate assessment method (i.e. one that would be easy to use and have a high predictive value) has been the subject of a plethora of studies and metaanalyses thus far $[4,5]$. The abundance of available tools goes to show that no ideal one-size-fits-all solution has yet been found $[4,15]$. The NRS 2002 scale, recommended for use in the mandatory nutritional assessment of Polish hospital patients, is one of such instruments. In their metaanalysis of 128 randomized clinical trials, Kondrup et al. [7] validated the patient- and treatment-related risk factors for malnutrition and proposed the NRS scale as a tool for their assessment. Its effectiveness has been confirmed by a number of studies [5, 7, 16-19]. Budzyński et al. [17], for instance, analyzed annual admissions to a selected full-profile

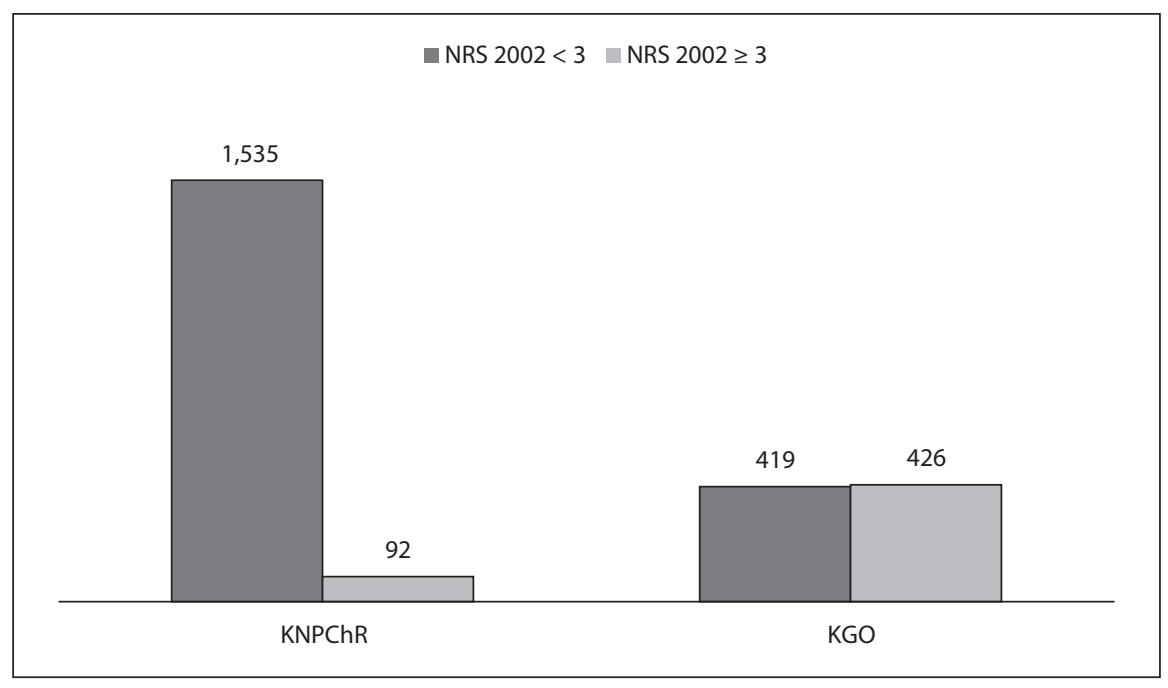

Figure 3. Nutritional assessment of surgical patients in the surgical wards of the Clinic of Breast Cancer and Reconstructive Surgery (KNPChR) and the Clinic of Oncological Gastroenterology (KGO) in 2015 
centre (more than 15,000 patients, 20,000 hospitalizations) and confirmed the utility of the NRS 2002 in the prognosis of both 14- and 30-day readmission (OR, respectively: 2.44, $p<0.0001$ and $2.37 p<0.001)$ and in-hospital mortality (OR 13.95, $p<0.001$ ). Schiesser et al. demonstrated that screening test scores can be shown to correlate with the frequency and severity of abdominal surgery complications, and it should be kept in mind that the risk of malnutrition in this patient group is particularly high [10]. In an EuroOOPS study conducted on 5,051 patients in 27 European broad-profile centres (surgery, internal medicine, oncology), Sorensen [18] confirmed the utility of NRS in the prognosis of postoperative complications. Gou [19], in turn, evaluated 337 patients who underwent stomach cancer surgery in a single center and found that complications were more frequently observed in the NRS $\geq 3$ group $(p<0.05)$. A metaanalysis of 11 prospective studies performed by Sun et al. [5] likewise confirmed the effectiveness of the scale in the risk assessment of surgical complications $(p<0.00001)$ and postoperative mortality $(p<0.00001)$ among patients treated with digestive tract surgery; those with a score of $<3$ were also shown to require shorter hospitalization times $(p=0.009)$ (Tab. V). Similar conclusions can be drawn from our analysis of 226 patients with upper and lower digestive tract malignancies. The lack of NRS 2002 scores for all patients (only $83 \%$ were studied) may undermine its validity, but a comparison with the Polish population [3] shows a similar distribution of malnutrition in the study group (51\% NRS $2002 \geq 3$ points).

Like many other studies, the current analysis suggests that the NRS 2002 scale may be very useful in the risk assessment of postoperative complications and conservative cancer treatment [16-19]. It is an extremely simple tool with a high predictive value. Even though nutritional assessments are now mandated by law, however, the proportion of patients who do not undergo such evaluation, especially in cancer wards, remains high (more than $90 \%$ ). This is bound to cause alarm, since cancer patients are at a particularly elevated risk of further malnutrition as a consequence of both the disease and its treatment [13]. The year-to-year increase in the number of completed NRS 2002 questionnaires, however, offers a glimmer of hope. Current ESPEN guidelines recommend that all cancer patients should be screened for malnutrition in order to prevent its adverse effects prior to cancer treatment [14].

\section{Conclusion}

The NRS 2002 scale is a useful tool for the prognosis of postoperative complications in the treatment of $\mathrm{Gl}$ cancers. Even though nutritional assessment is now required by law, not all patients, especially among those receiving systemic therapy, undergo such evaluation. The proportion of malnourished patients in the study group corresponds to
Table V. Utility of the NRS 2002 scale in predicting postoperative complications in GI tract surgery (according to Sun et al. [5])

\begin{tabular}{ll}
\hline $\begin{array}{l}\text { Risk of postoperative } \\
\text { complications }\end{array}$ & $\mathrm{OR}=3.13[2.51,3.90], \mathrm{p}<0.00001$ \\
$\begin{array}{l}\text { Risk of perioperative } \\
\text { mortality }\end{array}$ & $\mathrm{OR}=3.61[1.38,9.47], \mathrm{p}=0.009$ \\
Hospitalization time & $\mathrm{WMD}=5.58[4.21,6.95], \mathrm{p}<0.00001$ \\
\hline
\end{tabular}

OR — odds ratio; WMD — weighted mean difference

similar figures available for the Polish population in relevant literature, which confirms the reliability of the assessment. The utility of the NRS 2002 scale for individual cancers, types of surgical procedures, and in systemic therapy requires further research in the framework of prospective studies.

\section{Conflict of interest: none declared}

\section{Tomasz Olesiński, MD, PhD}

Clinic of Oncological Gastroenterology

Maria Skłodowska-Curie Memorial Cancer Center

and Institute of Oncology

Roentgena St. 5

02-781 Warsaw, Poland

e-mail:tolesinski@coi.pl

Received:13 Nov 2016

Accepted: 6 Feb 2017

\section{References}

1. Shpata V, Prendushi X, Kreka M et al. Malnutrition at the time of surgery affects negatively the clinical outcome of critically ill patients with gastrointestinal cancer. Med Arch 2014; 68: 263-267.

2. Tojek K, Frasz J, Szewczyk M et al. Ocena stanu odżywienia pacjentów hospitalizowanych w Katedrze i Klinice Chirurgii Ogólnej na podstawie formularza NRS 2002. Pielęgniarstwo Chirurgiczne i Angiologiczne 2009; (4): 144-150.

3. Talarek M, Szawłowski A. Ogólnopolski program oceny występowania niedożywienia u pacjentów z nowotworami układu pokarmowego i nowotworami głowy i szyi. Pol Przeg Chir 2007; 79: 343-352.

4. van Bokhorst-de van der Schueren MA. Guaitoli PR, Jansma E et al. Nutrition screening tools: does one size fit all? A systematic review of screening tools for the hospital setting. Clin Nutr 2014; 33: 39-58.

5. Sun Z, Kong X, Jing X et al. Nutritional Risk Screening 2002 as a predictor of postoperative outcomes in patients undergoing abdominal surgery: a systematic review and meta-analysis of prospective cohort studies. PloS One 2015;14:10: e 0132857. doi:10.1371/journal.pone.0132857.

6. Sungurtekin $\mathrm{H}$, Sungurtekin $\mathrm{U}$, Balci $\mathrm{C}$ et al. The influence of nutritional status on complications after major intraabdominal surgery. J Am Coll Nutr 2004; 23: 227-232.

7. Kondrup J, Rasmussen $\mathrm{H}$, Hamberg $\mathrm{O}$ et al. Nutritional risk screening (NRS 2002): a new method based on analysis of controlled clinical trials. Clin Nutr 2003; 22: 321-336.

8. Correia MI, Waitzberg DL. The impact of malnutrition on morbidity, mortality, length of hospital stay and costs evaluated through a multivariate model analysis. Clin Nutr 2003; 22: 235-239.

9. Pirlich $M$, Schutz T, Norman $K$ et al. The German hospital malnutrition study. Clin Nutr 2006; 25: 563-572.

10. Schiesser M, Muller S, Kirchhoff P et al. Assessment of a novel screening score for nutritional risk in predicting complication in gastro-intestinal surgery. Clin Nutr 2008; 27: 565-570.

11. Ravasco P, Monterio-Grillo I, Vidal PM et al. Dietary counseling improves patient outcomes: a prospective, randomized, controlled trial in colorectal cancer patients undergoing radiotherapy. $J$ Clin Oncol 2005; 23: 1431-1438.

12. Ottery F. Suportive nutrition to prevent cachexia and improve quality of life. Semin Oncol 1995; 22 (2 Suppl 3): 98-111. 
13. Andreyev HJ, Norman AR, Oates J et al. Why do patients with weight loss have a worse outcome when undergoing chemotherapy for gastrointestinal malignancies? Eur J Cancer 1998; 34: 503-509.

14. Arends J, Bodoky G, Bozzetti F et al. ESPEN Guidelines on Enteralnutrition: Non-surgical oncology. Clin Nutr 2006; 25: 245-259.

15. Velasco C, Garcia E, Rodriguez V et al. Comparison of four nutritional screening tools to detect nutritional risk in hospitalized patients: a multicentre study. Eur J Clin Nutr 2011; 65: 269-274.

16. Poulia K, Klek S, Doundoulakis I et al. The two most popular malnutrition screening tools in the light of the new ESPEN consensus definition of the diagnostic criteria for malnutrition. Clin Nutr 2017; 36: 1130-1135.
17. Budzyński J, Tojek K, Czerniak B et al. Scores of nutritional risk and parameters of nutritional status assessment as predictors of in-hospital mortality and readmissions in the general hospital population. Clin Nutr 2016; 35: 1464-1471.

18. Sorensen J, Kondrup J, Prokopowicz J et al. EuroOOPS: an international multicentre study to implement nutritional risk screening and evaluate clinical outcome. Clin Nutr 2008; 27: 340-349.

19. Guo W, Ou G, Li X et al. Screening of the nutritional risk of patients with gastric carcinoma before operation by NRS 2002 and its relationship with postoperative results. J Gastroenterol Hepatol 2010; 25: 800-803.
Annex 1. Nutritional Risk Screening (NRS 2002), final screening

\begin{tabular}{|c|c|}
\hline \multicolumn{2}{|c|}{ Impaired nutritional status } \\
\hline Score 0 - Absent & Normal nutritional status \\
\hline Score 1 - Mild & $\begin{array}{l}\text { Weight loss }>5 \% \text { in } 3 \text { months or food intake } \\
\text { below } 50-75 \% \text { of normal requirement in } \\
\text { preceding week }\end{array}$ \\
\hline Score 2 - Moderate & $\begin{array}{l}\text { Weight loss }>5 \% \text { in } 2 \text { months or BMI } 18.5-20 \\
+ \text { impaired general condition or } \\
\text { food intake } 25-60 \% \text { of normal } \\
\text { requirement in preceding week }\end{array}$ \\
\hline Score 3 - Severe & $\begin{array}{l}\text { Weight loss }>5 \% \text { in } 1 \text { month ( }>15 \% \text { in } \\
3 \text { months) or BMl }<18.5+\text { impaired } \\
\text { general condition or food intake } 0-25 \% \text { of } \\
\text { normal requirement in preceding week in } \\
\text { preceding week }\end{array}$ \\
\hline
\end{tabular}

Total score ............

Age if $\geq 70$ years: add 1 to total score above

Total score: .............
Severity of disease, increase in requirements

Score 0 - Absent Normal nutritional requirements

Score 1 - Mild

Hip fracture, chronic patients,

in particular with acute complications:

cirrhosis, COPD, chronic

hemodialysis, diabetes, oncology

Score 2 - Moderate

Major abdominal surgery, stroke, severe pneumonia, hematologic malignancy

Score 3 - Severe

Head injury, bone marrow

transplantation, intensive care patients (APACHE > 10)

COPD — chronic obstructive pulmonary disease; $\mathrm{BMI}$ — body mass index 